(1)

George Fox

UNIVERSITY
Digital Commons @ George Fox University

$1-22-2019$

U.S. Consumers' Perception of Asian Brands' Cultural Authenticity and Its Impact on Perceived Quality, Trust, and Patronage Intention

Sarah Song Southworth

Follow this and additional works at: https://digitalcommons.georgefox.edu/gfsb

Part of the Business Commons 


\title{
U.S. Consumers' Perception of Asian Brands' Cultural Authenticity and Its Impact on Perceived Quality, Trust, and Patronage Intention
}

\author{
Sarah Song Southworth \\ Department of Marketing, George Fox University, Newberg, Oregon, USA
}

\begin{abstract}
This study investigated the effectiveness of a brand marketing strategy that can be used by Asian brands originating from particularly emerging Asian countries to introduce themselves to the U.S. consumers. Specifically, the study examined how Asian-themed brand logos can enhance an Asian brand's cultural authenticity, perceived quality, brand trust, and patronage intentions. The results of a nation-wide survey of 570 U.S. consumers provided empirical support for the proposed relationship. The research provides empirical insight on how authentic "Asian-ness" could be one helpful way to position Asian brands in the U.S. marketplace. The study concludes with contributions, limitations, and future research opportunities.
\end{abstract}

\section{KEYWORDS}

Asian brand; brand logo; brand quality; brand trust: cultural authenticity; patronage intention

\section{Introduction}

For Asian brands, global expansion strategies into Western countries have prevalently been treated as a continental (Asian brand) instead of a national (e.g. Chinese or Indian brand) endeavor (Cayla and Eckhardt 2008; Roll 2006). A main reason may be that Asian brands are small in number (make up only 10\% of top 100 global brands) (Interbrand 2017) and thus need a unified alliance to strategize. Another reason may be owing to Western (e.g. American) consumers having a more favorable perception of Asian brands when they are presented by their continent of origin instead of the specific country of origin (Smith 1993). As early as the 1990s, Smith (1993) conjectured that other Asian brands expanding into the United States were able to leverage on the coat tail effect of Japan's established reputation for high quality of products.

The third reason, which is the basis of this study, is that Asian brands face a corporate challenge in today's Western marketplace to overcome a low-brand-quality perception. Although Asian brands originating from emerging countries (i.e. South Korea, China, and India) have drastically improved from their main role as manufacturers to branded retailers in the past two decades, they still face challenges in developing a competitive advantage in quality over other Western global retail players who have dominated the global market since the Industrial Revolution (Ben-Ur and Wang 2008; Birnik, Birnik, and Sheth 2010; Farhoomand 2009; Meyer and Shen 2010; Roll 2006). For these reasons, the author chooses to examine a strategy to build quality perception for Asian brands in this study.

Although successful Asian brands from emerging countries may not face challenges in communicating their intended message of brand quality and in building trust with their native or even regional consumers, the researcher suggests that, in order for them to globalize into Western countries, these Asian brands must have different global strategies for brand communication toward the Western consumers. For example, Herborist, a Chinese cosmetic brand, hired global brand managers to help formulate globalization strategies that were different from those intended for the Chinese market. The resulting campaign used a Chinese medicinal herb appeal together with 
the concept of "Yin and Yang" for marketing to global consumers. This differs from their marketing strategy toward Chinese consumers, where the brand had a brand positioning similar to Western competitors such as L'Oreal and Estee Lauder (Zhou 2011). Strengthening their positioning through Asian features while adding a westernized fragrance helped them to differentiate their brand from other Western brands and successfully grow. Herborist is now sold in many European countries at Sephora, a French cosmetic chain store with over US\$2 billion in annual sales (Zhou 2011). In this light, the previous research and current marketing practices suggest that Asian brands may be capable of using similar strategies to build positive brand quality perception and trust with Western consumers (Ben-Ur and Wang 2008; Kumar and Steenkamp 2013; Southworth and Kim 2015).

Perceived quality is defined as the "consumer's judgement about a product's overall excellence or superiority" (Zeithaml 1988, 3). It is essential for many businesses to succeed (Golder, Mitra, and Moorman 2012; Zeithaml 1988), not only because it strengthens consumers' perceived value of the product, but also because it influences the consumers' patronage behavior toward the brand (Pan and Zinkhan 2006; Song and Zinkhan 2003). Indeed, consumers are willing to pay a premium price for products or services they understand to be of high quality (Teas and Agarwal 2000). The past research shows that positive quality perception alleviates the perceived risks associated with purchasing any unfamiliar products or services (Southworth and Kim 2014; Yee, Ng, and Khoon 2011), and further helps develop long-term competitive advantages via consumers' trust and positive attitude toward the specific product, service, or brand (Boisvert and Ashill 2011; Eisingerich and Bell 2008). Thus, for Asian brands who now want to expand their market from home or regional markets to Western markets, it is particularly important for them to establish positive quality perception in the minds of their new consumers who may not be familiar with the brands.

Trust is another important factor if Asian brands from emerging markets are to achieve their mission to globalize their markets. A customer wants to be confident in their expectation that they will find what is anticipated in the brand (Barney and Hansen 1994; DelgadoBallester and Hernández-Espallardo 2008; Mayer, Davis, and Schoorman 1995). The literature suggests that for brands to build and strengthen trust with their consumers, high and consistent quality offerings, and genuine customer services are some of the important strategies that companies must offer (Chang and Chen 2008; Matzler, Grabner-Kräuter, and Bidmon 2006; Yoon 2002). Especially for Asian brands from emerging countries with little global recognition, gaining the trust from untapped/new Western consumers will be important.

Kumar and Steenkamp (2013) recently argued that Asian brands may need to highlight their cultural authenticity to improve consumers' trust, as well as their quality perception. Brand authenticity refers to the perception of what is genuine or real in the eyes of the consumer (Beverland and Farrelly 2010; Grayson and Martinec 2004). In this research, a brands' cultural authenticity is therefore defined as the perception of what is genuine or real in terms of the cultural origin of the brand in the eyes of the customer. What this means, Kumar and Steenkamp (2013) argue, is that Asian brands entering into the U.S. market may be better off being authentically "Asian" rather than trying to be like their Western or American counterparts. This concept has also been gaining attraction from other researchers in the brand communication literature (Ben-Ur and Wang 2008; Cayla and Eckhardt 2008; Kumar and Steenkamp 2013; Roll 2006).

The previously published research, however, does not specify how the cultural authenticity of brands can build a perception of high quality and trust among consumers. In addition, most of the existing literature on brand cultural authenticity seems to concentrate on the hospitality and tourism industries, where consumers' culturally authentic experiences are central to their success (Beverland and Farrelly 2010; Ooi and Stöber 2008; Waitt 2000). Thus, this research was designed to investigate how "Asian-ness" can be created and conveyed via brand communications to Western, namely the U.S. consumers. 
The cultural authenticity of "Asian-ness" is often presented by continent in the United States. Consequently, it is not difficult to find Asian restaurants such as Buddhalicious in North Carolina in which Chinese, Japanese, Indian, and Thai food are all served in one place, or Bamboo Asia in San Francisco in which Indian, Vietnamese, and Japanese food are served together.

From Time magazine's (2010) coverage of "The Best of Asia: Our annual guide to the region's finest delights for the mind, body, and soul" to the airing of "Asia's Got talent (as opposed to China's Got Talent-like Britain/ America's Got Talent)," the ever-present practice of blurring the lines of country of brand origin aligns with the current perceptions of the U.S. consumers. For example, Magnusson, Westjohn, and Zdravkovic (2011) found in their study titled "What? I thought Samsung was Japanese" that the U.S. consumers are aware of the origin of Asian brands by continent, not necessarily by country. In light of the current practices and consumer perceptions, this study seeks to understand how emerging Asian brands from namely China and India (two seemingly different brand origins) can share a perception of Asian-ness which is culturally authenticated in the United States.

Furthermore, the research examines how this cultural authenticity of Asian brands affects Western, namely United States, consumers' quality perception, trust and, in turn, their brand patronage intentions. This article starts with the literature review and research method. The results of the studies follow, along with the article's contributions, limitations, and future research opportunities.

\section{Literature review}

As aforementioned, Asian brands face additional challenges in competing with quality perceptions against other Western brands in the global marketplace. In light of this challenge, the author uses the framework of FCCP (foreign consumer culture positioning), where Asian brands can appeal through cultural "foreignness" (e.g. Herborist globally using its Chinese medicinal herb appeal) to help build quality perception in the Western market. The FCCP is used instead of the other two consumer culture-positioning strategies (Alden, Steenkamp and Batra 1999), including GCCP (global consumer culture positioning), where brands create a global player appeal (e.g. Zara using English as the language with same products, labels across the globe), and LCCP (local consumer culture positioning), where brands position themselves as the local players (e.g. Lays as Sabritas in Mexico).

Studies such as Hornikx and Meurs' (2017) help support the author's proposal that the concept of appealing through FCCP may have more favorable outcomes (compared to the other two positioning strategies) especially when the cultural appeal helps to authenticate and accentuate the COO (country-of-origin) of the brand. Specifically, Hornikx and Meurs (2017) demonstrated how the foreign language (using FCCP) created associations with the $\mathrm{COO}$ which led to a higher quality perception, positive attitude, and purchase intention toward the marketed product. Thus, although the other two positioning strategies (GCCP and LCCP) may have been more appropriate for Asian brands' local and regional consumers, the author proposes that the appeal of FCCP using cultural authenticity may be more effective in competing with other Western brands in the U.S. market.

\section{Brand's cultural authenticity}

Given that brand authenticity embodies what consumers perceive to be real, genuine, or true about a brand (Beverland and Farrelly 2010; Grayson and Martinec 2004), different groups of consumers may form different perceptions when brands offer their messages. Therefore, when a brand wants to establish authentic brand messages, it has to be staged for the right audience and in the right contexts (Ooi and Stöber 2008). This is particularly true if the brand tries to expand its market to different cultural markets. Combining the influence of both foreign and indigenous cultures might be desirable (Beverland and Farrelly 2010; Grayson and Martinec 2004; Munoz, Wood, and Solomon 2006; Rose and Wood 2005; Ooi and Stöber 2008). For example, Panda Express, a Chinese American fast food restaurant chain, demonstrates the successful combination of two cultures for its brand's success. It 
projects an image of authentic Chinese culture and food, yet does not offer true authentic Chinese cultural experience when consumers are at the restaurant.

Thus, some well-known Asian brands have focused on what is authentically Asian in the minds of Western consumers. For example, Korean Air hires female flight attendants who are younger than 27 years of age, with attractive looks and within certain height and weight requirements (Korea Times 2012). It also specifies that successful flight attendant candidates must have advanced sets of skills, including English and college education (Korea Times 2012). Although this may not be considered authentically Korean, Korean air hopes to reflect the "glamor, grace, and delicacy of the flight attendants" while exuding "the etiquette and loyalty of Confucianism" (Korea Times 2012). Similarly, with other authentic components, such as Korean food, Korean movies, and a Korean way of customer services, the whole experience of Korean Air's service offers what is uniquely Korean (Korean Air 2017). Its ultimate goal is to promote Korean excellence by becoming "recognized by people around the world for providing high* quality service and excellence in flight" (Korean Air 2017).

Most recently, Southworth and Kim (2014) demonstrated that an Asian-themed as opposed to the Western-themed, bottle design of a Chinese cosmetic brand positively influenced the U.S. consumers' perceived quality of an unfamiliar Asian brand. Regardless of the specific nature of Asian authenticity, the researcher agrees that cultural authenticity allows consumers around the world to connect and experience a part of another culture that is not easily available in their daily lives (Beverland and Farrelly 2010; Özsomer and Altaras 2008).

\section{Brand logotype and Brand cultural authenticity}

How, then, can a logo establish and enhance its brand's cultural authenticity? The brand logo refers to "the graphic design that a [brand] uses to identify itself" (Pittard, Ewing, and Jevons 2007, 458) and has two components: verbal (the logotype) and visual (its mark) (Saikawa and Onisawa 2014). It communicates the core values, missions, messages, and even the cultural heritage of a brand and, further, has a powerful influence on the consumer perceptions on the brand (Ailawadi and Keller 2004; Roll 2006; Salciuviene et al. 2010; Yorkston and Menon 2004). Thus, corporate logos are used to create desired brand associations (Van Riel and Van Den Ban, 2001).

The brand logotype is the "name that is set in a distinctive typeface but is devoid of secondary embellishments" (Doyle and Bottomley 2006, 112). It is usually presented to consumers as the brand name. In this study, the researcher suggests that the language of the brand logotype can be used to convey the brand's cultural authenticity (Larsen et al. 2002; Marian and Neisser 2000). Thus, some brands may choose to have an English logotype to appeal to consumers throughout the world (using GCCP), whereas others may choose to have their brand logotypes in their native language (using FCCP). For example, the LG Corporation, a South Korean conglomerate corporation, was called Lucky Goldstar when it was first established in 1958 (LG Corporation 2015). An interesting fact here is the company's official Korean name was Lucky GeumSeong (which means Goldstar in Korean), yet the products were sold and exported under the name of Lucky Goldstar (LG Corporation 2015). Clearly, changing GeumSeong to Goldstar indicates the company's intention to appeal to global consumers by using English in their brand logotype. However, one of the most popular cosmetic brands in Asia, Sulwhasoo, kept the authentic Korean language in its brand logotype as a way of emphasizing the brand's unique technology and heritage built from Korean herbal medicine culture (Sulwhasoo 2018). Today, Sulwhasoo is marketed to people around the world, including consumers who do not understand the Korean language.

Given this market situation, the researcher investigated the effect of a foreign-language brand logotype on cultural authenticity. The brand name in foreign language has been found to influence the consumer perceptions of restaurants' food authenticity in the U.S. market (Magnini, Miller, and Kim 2011). Dong and Helms (2001) found that the brand logotype in English (compared to the one in Chinese) generated a more favorable brand image for Chinese 
consumers, especially for the educated younger generations. The author explained that the familiarity of the English language in the brand logotype was one of the reasons why educated and young Chinese consumers favored such a brand. One might say from this finding that as it was a U.S. brand, English was the better choice for its brand logotype because it emphasized American authenticity for a U.S. brand. Analogously, this may be the same reason Louis Philippe, one of India's top apparel brands for men, brand itself as having a French-influenced design, with a French name inspired by the King of France on its logo. More recently, Salciuviene et al. (2010) researched the U.S. consumers' perceptions on brand names in English, French, and German languages and found that French brands were perceived to be the brands with more luxury products than utilitarian ones, even more so when the French language was used in the brand's logotype. That is, the perceived decadence of French culture seemed to have been associated with the French language used in the brand logo. One might therefore argue that the language of the brand logotype shapes the brand's cultural authenticity.

Furthermore, China and India were timely used as the two brand origins for testing the perception of Asian brands. These two countries are experiencing the fastest growth in economy in Asia, and have an increasing number of emerging brands expanding globally into not only Asian but Western nations (e.g. Alibaba, a Chinese company in e-commerce, retail, technology conglomerate, and Tata Group, an Indian company in multiple industries including chemicals, engineering, IT Systems, telecommunications, steel industry, etc.) (Interbrand 2017).

Hence, the study hypothesized:

H1: The combination of the Asian language and English as opposed to English alone used in brand logotype affects the Asian (i.e. Chinese and Indian) brand's cultural authenticity.

\section{Brand mark and cultural authenticity}

The brand mark is another key way to communicate a brand's cultural authenticity. The brand mark is the visual element of the brand logo (Saikawa and Onisawa 2014). Given the power of the brand logo on brand communications, the visual design aspects of logo marks have been the focus of researcher, specifically for the success of Western brands in the Asian consumer market (Henderson et al. 2003; Schmitt 1995).

The author draws examples from veteran Korean brands that illustrate how brand logo has been used in global expansion to imply cultural authenticity. In the case of the LG Corporation, the Lucky Goldstar logo had a crown with five stars until the creation of a new logo when the name was formally changed to LG Corporation in 1997 (LG Corporation, 2015). As with the brand logotype, the logos of neither Lucky Goldstar nor LG communicated any Korean cultural authenticity. Meanwhile, Sulwhasoo uses a brand logo with a specific style that represents traditional Korean culture and an herbal medicine feel (Sulwhasoo 2018). According to Alexander (2009), the commitment to a certain visual or design style is one of the key factors for building cultural authenticity. One might say, then, that the LG Corporation uses its brand logo to disassociate from the brand's Korean cultural heritage, whereas Sulwhasoo uses theirs to enhance the brand's Korean authenticity. Therefore, the study hypothesized:

$\mathrm{H} 2$ : The cultural design (Asian compared to Western) of the brand logo mark affects an Asian (i.e. Chinese and Indian) brand's cultural authenticity.

\section{Brand cultural authenticity and perceived quality}

Cohen (1988) emphasizes that authenticity is a type of quality that is perceived by individual consumers, and it emerges from their own personal experiences. Alexander (2009) likewise uses the term quality commitments to explain the attribute of brand authenticity. Much research shows that a brand's perceived authenticity also positively affects consumers' perceptions of brand quality (Alexander 2009; Brown, Kozinets, and Sherry 2003; Grayson and Martinec 2004; Peñaloza 2000; Thompson and Tambyah 1999).

Formally, brand quality is defined as the global evaluation of a brand, particularly in regards to 
the characteristics of being reliable, dependable, and beneficial (Agarwal and Teas 2001; Holbrook and Corfman 1985; Zeithaml 1988). Özsomer and Altaras (2008) stressed that global brands may use their cultural authenticity to "deliver cultural myths with global appeal" (p. 8), which can in turn help form the cultural capital of the brands. This cultural capital could then be transformed into positive perceptions of quality for brands. Steenkamp, Batra, and Alden (2003) also found that this cultural capital has a positive effect on both purchase likelihood and perceived brand prestige. Thus, if an Asian brand wants to target the U.S. consumers, the brand must be able to communicate its cultural authenticity as an Asian brand to have positive influence on consumers' quality perception. Consequently, the study hypothesized:

H3: An Asian (i.e. Chinese and Indian) brand's cultural authenticity positively affects the U.S. consumers' perceived brand quality.

\section{Brand cultural authenticity and Brand trust}

Brand trust is viewed as the confidence with which a customer can expect to find what he or she desires in the brand (Barney and Hansen 1994; Delgado-Ballester and HernándezEspallardo 2008; Mayer, Davis, and Schoorman 1995). Trust is crucial for building brands, and Kumar and Steenkamp (2013) recently found that brands from China and India received low scores on brand attributes, such as trustworthiness, innovativeness, and desirability, from Western consumers across all brand categories. Given this type of challenge, the literature suggests that one of the effective ways for an Asian brand to gain trust among consumers in new markets is by building the brand's cultural authenticity. Eggers et al. (2013) found that the authenticity of a brand can make a positive impact on trust, which in turn positively can impact the growth of smalland medium-sized enterprises across industries. More recently, Napoli et al. (2014) also found that a consumer who rated a brand as culturally authentic also perceived it to be credible. Similar relationships are expected for Asian brands from emerging countries as well. Consequently, the study hypothesized:

H4: An Asian brand's cultural authenticity positively affects brand trust perceived by the consumers.

\section{Brand quality and Brand patronage intention}

Brand patronage behavior refers to the consumer's choice to eventually become loyal to a brand (Dodds, Monroe, and Grewal 1991; Pan and Zinkhan 2006). As the actual patronage behavior cannot be measured for a brand with which consumers lack any prior experience, patronage intention, an antecedent of patronage behavior, is suggested to be used as a proxy for patronage behavior in the literature (Baker et al. 2002; Grewal et al. 2003; Kaul, Sahay, and Koshy 2010). Thus, patronage intention is a focus in this study and is defined as the intention to purchase or recommend the brand to others (Grewal et al. 2003). Building patronage intentions is important for any new brands or new players in the marketplace. By definition, patronage intention is concerned with the long-term success of a brand as it captures consumers' loyalty. Loyalty is not created in a short-term period (Aaker 1996), whereas purchase intention tends to measure the consumers' intention toward short-term or more immediate purchases (Pan and Zinkhan 2006).

In this light, because it is an outcome of positive perceived quality built by a brand's cultural authenticity, consumers' patronage intention of a brand is a focus in this study. In fact, Chaudhuri and Holbrook (2001) and Hem and Iversen (2003) stressed that it is crucial to investigate the effect of perceived quality on consumers' patronage intention because the end goal of a highquality perception is to strengthen consumer loyalty. Furthermore, perceived quality has been used as the antecedent to consumers' brand patronage intention in many different studies. For example, in Grewal et al.'s (1998) study, perceived brand quality was found to indirectly influence consumers' purchase intention through perceived value. Baker et al. (2002) also found that service quality perception had a positive influence on patronage intentions, whereas the merchandise quality perception indirectly 


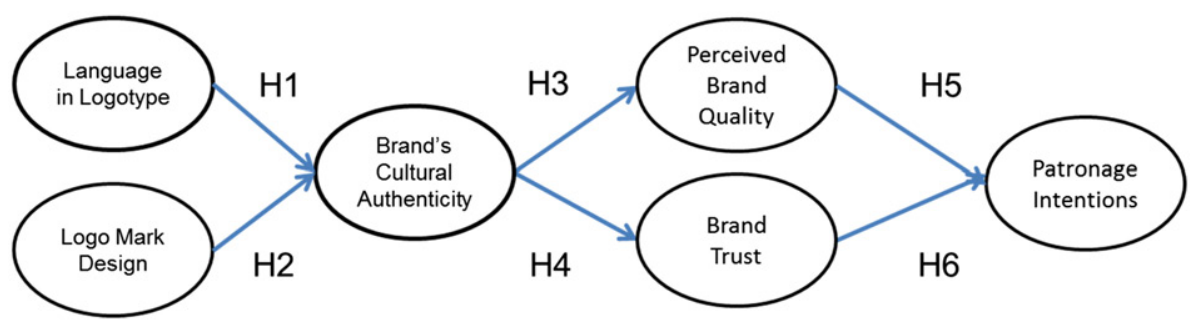

Figure 1. The study research model.

influenced patronage intentions. Similarly, the study by Miyazaki Lassar, and Taylor (2007) examined the positive impact of online brand service quality perception on patronage intentions. A similar relationship is expected for Asian brands. Therefore, the study hypothesized:

H5: An Asian (i.e. Chinese and Indian) brand's perceived quality positively affects consumers' patronage intentions toward the Asian brand.

\section{Brand trust and Brand patronage intention}

Consumer trust of a brand is also discussed as an important factor in building consumers' brand patronage intentions (Christodoulides et al. 2006; Delgado-Ballester and Hernández-Espallardo 2008; Keller 1993; Kim, Sharma, and Setzekorn 2002; Rios and Riquelme 2008). Much research supports the positive relationships between brand trust and consumers' patronage intentions. For example, Jones and Kim (2010) found that gaining trust in an online setting for a brand can lead to consumers' positive off-line patronage intention for the brand. In Keeling, McGoldrick, and Beatty's (2010) study, the researcher found that task- and social-oriented brand communications through interactive avatars positively contributed to building consumers' trust of the brand's website, which in turn positively influenced consumers' patronage intentions. Similarly, Kim, Ferrin, and Rao (2008) and Verhagen, Meents, and Tan (2006) showed that building and enhancing trust is crucial for online brands' success in today's marketplace. In the context of introducing a new brand to the Indian marketplace, Kaul, Sahay, and Koshy (2010) found that the initial trust built by young Indian male consumers had a strong positive effect on their patronage intentions for the new brand to compete against established brands. Consequently, the study hypothesized:
H6: Brand trust positively affects consumers' patronage intentions toward an Asian (i.e. Chinese and Indian) brand.

Figure 1 shows the study's hypothesis model explaining the relationship between a brand's cultural authenticity - built by the brand logo mark and the language used in the brand name - and consumers' perceived brand quality, brand trust, and brand patronage intentions.

\section{Research methods}

For the purpose of the study, the researcher used a 2 (Asian-themed vs. Western-themed logo mark) by 2 (English only vs. a blend of English and Asian language logotype) between-subjects factorial experimental design. Experimental research design is valuable in examining causal relationships among variables, and to predict the respondents' perceptions within specific scenarios (Grabe and Westley 2003). Thus, the experimental design was deemed appropriate in light of the objective of the study to examine the predictive perceptions of the U.S. market when presented with a new brand logo offered by Asian brands from emerging countries.

\section{Stimuli development}

Both the logo marks (the visual element of the logo) and the logotypes (the verbal component of the logo) were manipulated to create brand logos representing Chinese and Indian cultural authenticity, respectively. A total of 24 versions of Asian-themed brand logos showing Chinese and Indian cultural authenticity were designed to introduce message variability in the study stimuli. In any type of message-related experimental research, each message stimulus hosts an infinite number of attributes and, thus, it is difficult to 
isolate a message stimulus on just one attribute (Thorson, Wicks, and Leshner 2012). Having more than one message stimuli in the experimental design reduces the between-message variance to random error and this technique allows the researcher to generalize the results to a greater population than a single-message experimental design (Thorson, Wicks, and Leshner 2012).

The brand logotypes (the verbal component) were manipulated comparing the use of English alone (i.e. Dila) to the use of both English and the foreign language (i.e. Dila 迪拉, Dila दलि to examine its impact on cultural authenticity. Using both English and the native language in logotypes is a standard strategy used by Asian brands (i.e. Herborist 佰草集, Bank of China 中 国银行; Uniqlo ユニクロ), but its effectiveness has not been researched (Dong and Helms 2001; Martin 2002; Ustinova and Bhatia 2005).

In this study, fictitious Asian brand names were created for the logotypes. The brand names had to show pronunciations, which are both passable for Chinese and Indian. This was done to ensure confounding factors associated with the brand origin effect, yet to still capture brand names that sounded both Chinese and Indian. Fictitious names were also necessary to reduce confounding factors associated with existing brand name associations. With these factors in mind, the research team decided to use Chinese (Mandarin) and Indian (Sanskrit, the base for all other languages in India) languages when creating brand logo stimuli.

Initially, 10 brand names were formulated with research assistants who are native to China and India to achieve the goals stated above and to ensure these are possible brand names they could easily see in their native countries. None of these names had any actual meanings or values. However, all names had to be naturally pronounceable in both Chinese and Indian. In total, 7 out of 10 brand names were chosen in consensus. Next, the research team conducted a pilot test to make sure these brand names were not country specific, neither Chinese nor Indian. In addition, the Bodoni MT font was used for the logotype. This font type is the 5th most commonly used font by graphic designers and is widely accessible in publishing programs (Cass 2008).

Next, the pilot test included asking 23 undergraduate students in a large Midwest U.S. university to identify a specific country that they could associate when they were first exposed to the brand names. As a result, the three brand names Ami, Nici, and Dila were chosen from the seven brands names for the next step. Next, the logo marks were manipulated.

For the logo mark, two Asian-influenced designs were developed to introduce message variability, as mentioned earlier. The Asian design elements included the traditional Asian coin with geometry motifs and the lotus flower using the colors black and red. The two Westernthemed design elements included the star with circle and diamond motifs using the colors black and blue. The colors black and red are often used together by Asian brands (both Chinese and Indian). These colors have been associated in past literature with Asian colors (Jacobs et al. 1991) and have been historically used and preferred by the Asian audience (Madden, Hewett, and Roth 2000). For Western brands, the use of blue and black has been used and preferred by the Western audience (Madden, Hewett, and Roth 2000), and hence it is prevalently used in the brand logos. In addition, the Asian designs tend to have rounded shapes, whereas the Western design, more angular shapes (Zhang, Feick, and Price 2006). Furthermore, commercially, Asian brands tend to create logos with rounded shapes (i.e. lotus flower and coin shape), whereas the Western brands tend to create logos with angular shapes (i.e. star or diamond shapes).

Overall, an aggregate of 24 brand logos was developed. There were four different brand logo mark designs (two for Asian-inspired design and two for Western-inspired design). These four brand logo marks were then paired with two different language logotypes for the three brand names, Ami, Dila, and Nici (the English only or the mix of English and foreign language), resulting in 24 distinct brand logos. Again, the multiple options for the logotype, logo marks, and brand names were created to ensure message variability. 
Table 1. Dependent measurement items.

\begin{tabular}{|c|c|c|}
\hline Variable/source & Items & Cronbach's alpha $(\alpha)$ \\
\hline Cultural authenticity (Napoli et al. $2014 ; \alpha=.79$ ) & $\begin{array}{l}\text { The brand exudes a sense of tradition. Disagree (1), Agree (7) } \\
\text { The brand reinforces and builds on long-held traditions. Disagree (1), Agree (7) } \\
\text { The brand reflects a timeless tradition. Disagree (1), Agree (7) }\end{array}$ & .95 \\
\hline Brand quality (Agarwal and Teas $2001 ; \alpha=.94$ ) & $\begin{array}{l}\text { This brand is likely to be reliable. Disagree (1), Agree (7) } \\
\text { The product from this brand is likely to be of high quality. Disagree (1), Agree (7) } \\
\text { This product from this brand is likely to be dependable. Disagree (1), Agree (7) }\end{array}$ & .96 \\
\hline Brand trust (Verhagen et al. 2006; $\alpha=.98$ ) & $\begin{array}{l}\text { I expect the brand to be dependable. Disagree (1), Agree (7) } \\
\text { I expect the brand to be reliable. Disagree (1), Agree (7) } \\
\text { I expect the brand to be honest. Disagree (1), Agree (7) } \\
\text { I expect the brand to be trustworthy. Disagree (1), Agree (7) }\end{array}$ & .97 \\
\hline Patronage intention (Grewal et al. 2003; $\alpha=.88$ ) & $\begin{array}{l}\text { I am likely to shop for this brand. Disagree (1), Agree (7) } \\
\text { I am likely to purchase a product from this brand. Disagree (1), Agree (7) } \\
\text { I am likely to recommend this brand to others. Disagree (1), Agree (7) }\end{array}$ & .96 \\
\hline
\end{tabular}

\section{Manipulation check}

A pretest $(n=100)$ was conducted to check the manipulation of the four logo mark designs developed in this study. To ensure that there is a distinct difference between the Asian and the Western designs, pretest respondents were exposed to one of the four logo mark designs. There was a significant difference in the perception of cultural authenticity between the Asian and the Western designs $[t(98)=2.24, p<.05]$. On a scale from 1 to 7 , the brand logos with the two Asian themes had a mean of 4.59 $(S D=1.19)$, whereas the brand logos with the two Western themes had a mean of 4.01 $(S D=1.39)$. With this result, the four logo mark designs were chosen for the main experiment stage. Additionally, the statistic results showed that the two Asian languages with different brand origins (Chinese and Indian) used in the stimuli did not affect the respondents' overall perceptions of the brand logo's cultural authenticity $(p=.20)$, brand quality $(p=.75)$, brand trust $(p=.86)$, and patronage intentions $(p=.64)$, eliminating potential confounding factors of brand origin effects that may arise from the brand being from China or India.

In addition, different product categories were tested in the study to account for generalizability including the following three categories (from soft goods to hard goods): (1) soft drinks such as soda and small hygiene products such as toothpaste; (2) jeans and athletic shoes; and (3) television and computer. The results showed that there was no variability in the respondents' overall perceptions of the brand logo's cultural authenticity $(p=.54)$, brand quality $(p=.46)$, brand trust $(p=.63)$, and patronage intentions $(p=.99)$, among the different product categories presented.

\section{Instrument development}

The measurement items (table 1) for the dependent variables were adapted from the previous literature with reliabilities $>.79$, and all used 7-point Likert-type scales. Napoli et al.'s (2014) three items for cultural authenticity $(\alpha=.79)$ was adopted, where a higher score indicated a higher level of authenticity. The measure of perceived quality (three items) was adapted from Agarwal and Teas' (2001) study $(\alpha=.94)$, with a higher score indicating higher brand quality. Brand trust was measured using the four items adapted by Southworth and Kim (2014) $(\alpha=.98)$. Patronage intention was measured using the three items from Grewal et al.'s (2003) study $(\alpha=.88)$.

\section{Reliability}

All items had high internal reliabilities with the following Cronbach's $\alpha$ s (table 1): .95 for cultural authenticity $(M=4.26 ; S D=1.37), .96$ for perceived quality $(M=4.52 ; S D=1.36), .97$ for brand trust $(M=4.65 ; S D=1.37)$, and .96 for patronage intentions $(M=4.10 ; S D=1.50)$.

\section{Data collection and analysis procedure}

A random sample was used, recruiting respondents (age of 18 years or older) nationwide in the United States through Qualtrics (a renowned survey agency) in summer of 2015. Initially, email invitations were sent with a URL link to the survey webpage which automatically randomizes the different brand logo designs. When each participant 
Table 2. Demographic profile of the study participants.

\begin{tabular}{llcc}
\hline Variable & \multicolumn{1}{c}{ Category } & Freq. & Percent \\
\hline Age (years) & $18-24$ & 77 & 13.51 \\
& $25-44$ & 192 & 33.68 \\
& $45-64$ & 196 & 34.39 \\
& $65+$ & 105 & 18.42 \\
& Total & 570 & 100 \\
Region & Midwest & 123 & 21.58 \\
& Northeast & 103 & 18.07 \\
& South & 216 & 37.89 \\
& West & 128 & 22.46 \\
& Total & 570 & 100 \\
& & & \\
Gender & Male & 277 & 48.6 \\
& Female & 293 & 51.4 \\
& Total & 570 & 100 \\
& & & \\
Ethnicity & White/Caucasian & 462 & 81.05 \\
& African American & 53 & 9.3 \\
& Hispanic & 28 & 4.91 \\
& Asian & 16 & 2.81 \\
& Native American & 2 & 0.35 \\
& Pacific Islander & 1 & 0.18 \\
& Other & 8 & 1.4 \\
& Total & 570 & 100 \\
\hline
\end{tabular}

clicked on the link, he or she was exposed to one of the four randomly assigned conditions (a combination of either a(n) Asian-themed logo mark or Western-themed logo, and either a(n) English or mix of English and Asian language logotype). The only context which the respondents received was: "Chinese (or Indian) brand below offers products such as (soft drinks such as soda and small hygiene products such as toothpaste, jeans and athletic shoes, or television and computer)." Questions regarding the dependent measures and demographics followed.

The complete descriptions of the respondents' gender, age, and primary regions are itemized in table 2. The respondents received incentives from Qualtrics. Within 2 weeks, a total of 570 responses were collected. Qualtrics ensured complete responses and hence no missing data were found. There was an even distribution in gender (51\% female, $49 \%$ male) with a mean age of 47 years $(S D=16.91)$, ranging from 18 to 86 . Participants were predominantly Caucasian (81\%), followed by African American (9\%), Hispanic (5\%), and Asian (3\%). Furthermore, 38\% of them were from the South region of the United States.

\section{Results}

As conducted in the manipulation check, the variability of the U.S. respondents' perceptions for Indian and Chinese brands was tested again. The results showed that the different brand origins (Chinese and Indian) used in the stimuli did not affect the respondents' overall perceptions of the brand logo's cultural authenticity $(p=.39)$, brand quality $(p=.81)$, brand trust $(p=.24)$, and patronage intentions $(p=.89)$, demonstrating that there is no difference between how Chinese or Indian brands are perceived in terms of cultural authenticity, brand quality, brand trust, and patronage intentions.

The ANOVA analyses revealed a statistically significant main effect for the brand logo design on the brand's cultural authenticity $(F(1,569)=$ 13.01, $p<.001)$. The logo mark with the Asian motif had a higher perception of cultural authenticity $(M=4.47 ; S D=1.33)$ than that of the Western motif $(M=4.06 ; S D=1.39)$. However, the main effect for the language on the brand's cultural authenticity was not significant $(p=.76)$. Therefore, H1 was supported, but H2 was not supported.

Confirmatory factor analysis (CFA) and structural equation model fit (SEM) were conducted for the four hypotheses. Maximum Likelihood Estimation was used in STATA V. 13 to analyze all available information in the data set. The following criteria suggested by $\mathrm{Hu}$ and Bentler (1999) was used to determine model fit.: CFI (Comparative Fit Index) $\geq .95$, Non-Normed Fit Index $\geq .95$, RMSEA (Root Mean Square Error Approximation) $\leq .06$, and SRMR (Standardized Root Mean Square Residual $) \leq 0.08$.

The results of the CFA after the four-item removal showed a good fit $\left(\chi^{2}(54)=111.02\right.$, $p<.001, \quad \mathrm{CFI}=.99, \quad \mathrm{TLI}=.99, \quad \mathrm{RMSEA}=.04$, SRMR $=.01)$. The AVE of each latent construct was also $>.56$, in which the cutoff criterion was .50 or higher (Hair, Ringle, and Sarstedt 2011). In addition, the AVE was higher than the construct's highest squared correlations with other latent constructs, establishing discriminant validity (Hair, Ringle, and Sarstedt 2011).

Following CFA, the path model established relationships among cultural authenticity, brand quality, brand trust, and patronage intentions. These hypothesized structural models were estimated by observing the variance-covariance matrices. Overall, the SEM results suggested 
Table 3. Unstandardized coefficients, estimated standard errors, and standardized coefficients.

\begin{tabular}{|c|c|c|c|c|c|}
\hline Hypothesis & Path & $B$ & S.E. & $\beta$ & $z$ \\
\hline H3 & Cultural authenticity $\rightarrow$ Brand quality & $0.79 * * *$ & 0.04 & $0.79 * * *$ & 41.8 \\
\hline $\mathrm{H} 4$ & Cultural authenticity $\rightarrow$ Brand trust & $0.80 * * *$ & 0.04 & $0.75^{* * *}$ & 34.7 \\
\hline H5 & Brand quality $\rightarrow$ Patronage intentions & $.46^{* * *}$ & 0.1 & $0.39 * * *$ & 4.39 \\
\hline H6 & Brand trust $\rightarrow$ Patronage intentions & $.48^{* * *}$ & 0.1 & $0.44^{* * *}$ & 4.95 \\
\hline
\end{tabular}

a good fit $\left(\chi^{2}(54)=161.48, p<0.001, \mathrm{CFI}=.99\right.$, $\mathrm{TLI}=.99, \mathrm{RMSEA}=.06, \mathrm{SRMR}=.03)$. That is, the brand's cultural authenticity showed statistically significant positive effects on consumers' perceived quality $(\beta=.79, z=41.84, p<.001)$ and brand trust $(\beta=.80, z=34.69, \quad p<.001)$. Consumers' perceived quality $(\beta=.39, z=4.39$, $p<.001)$ and brand trust $(\beta=.44, z=4.95$, $p<.001)$ also had statistically significant positive impacts on consumers' patronage intentions, supporting the study hypotheses 3, 4, 5, and 6 . Standardized parameter estimates $(\beta)$ and unstandardized parameter estimates $(B)$ are listed in table 3 .

\section{Conclusions}

In light of the rising economic power of the emerging Asian countries in the global marketplace, this study investigated one of the effective brand communication strategies that Asian brands may want to utilize when presenting themselves to Western, specifically the U.S. consumers - the strategic use of branding. Should an Asian brand make a show of its cultural authenticity? Should a brand use more familiar Westernthemed brand communication strategies? To find the answers to these questions, the study examined how the perceptions of cultural authenticity could be created via brand logo manipulations and how it impacts consumers' perceived quality, trust, and patronage intentions.

The results of a nationwide survey of the U.S. adult consumers via a survey company, Qualtrics, suggested that a brand logo can be perceived to be more culturally authentic when it comes to Asian-inspired brand logos than Westerninspired ones. Through successful manipulations of carefully selected colors and shapes, after accounting for message variability, cultural authenticity was created for Asian brands in this study, and such cultural authenticity was found to enhance the U.S. consumers' perceived quality, brand trust, and patronage intentions. However, the use of Asian language logotype in addition to English language in a brand logo did not have any influence on consumers' perceptions of the brand's cultural authenticity.

The findings of this study have a few critical contributions and implications. First, the findings of the study make theoretical contributions to the literature by showing how graphical elements of brand logos could affect consumers' perceptions of cultural authenticity and therefore their perceived quality and trust in the brands. The extant literature still lacks examination of what makes up the cultural authenticity of a brand, and this study fills the gap by showing how visual components of the brand logo could be a critical cue for communicating the brand's cultural heritage to consumers.

Valuable findings were also revealed through the manipulation checks in this study. Namely, there was no difference in the U.S. respondents' perceptions of cultural authenticity, brand quality, trust, and patronage intentions whether the respondents were presented with $\mathrm{a}(n)$ Chinese or Indian brand. Furthermore, three different product categories were tested in the study to test for generalizability: (1) soft drinks such as soda and small hygiene products such as toothpaste; (2) jeans and athletic shoes; (3) television and computer. The results showed that there was no variability in the respondents' perceptions of in cultural authenticity, brand quality, trust, and patronage intentions among the different product categories presented. A thought-provoking point about this result is that even technology products were more appealing when the Asian-ness was present in the logo. This implies the importance of design across product categories which has yet to be experimented with. Most global Asian technology brands such as Samsung, LG, Lenovo, and Tata group try to look Western in appearance 
(using GCCP). With more acceptance of technology brands from Asian brands, it may be timely to further focus on how branding Asian-ness (using FCCP) can impact Asian technology brands.

Second, the study empirically shows how authentic "Asian-ness" could be helpful to gain trust and build high-quality perception among the U.S. consumers, filling a gap in the literature, most of which focuses on the role of Western brands in Asian consumers' perceptions. In today's global marketplace, Asian products may no longer be perceived to be low in quality or copies of Western invention. Because of recent successes of Asian brands especially from countries like Japan and South Korea, perhaps, the U.S. consumers already have higher quality expectations for Asian brands as also previously observed by Smith (1993). Therefore, trying to look like a Western brand (i.e. less culturally authentic by using a GCCP or even LCCP appeal) to Western consumers may no longer necessarily be the only effective communication strategy for Asian brands from emerging countries in today's marketplace. The study findings provide empirical support for this position.

Third, the study showed interesting relationships between the colors and the shapes of brand logo marks when creating Asian cultural authenticity or Asian-ness. The study on the communication of brands' identities, not to mention their cultural authenticity, via various graphic elements is limited in today's literature, as much research has focused on which messages - mostly texts or oral - to deliver to gain consumers' trust or patronage intentions. In today's society where so many visual stimuli are present around consumers' lives and environments, the study findings show that a logo itself, especially a logo mark, may offer a unique power to communicate the brand's cultural authenticity, in spite of being small in size.

Fourth, the study finds that building perceived brand quality and trust through the brand's cultural authenticity is an effective way to ultimately build patronage intentions for Chinese and Indian brands. For Chinese brands, there are currently three top brands among the top 100 global brands (Interbrand 2017). Despite many different attempts, other Asian brands, such as Jianlibao (a beverage brand in China) and Li Ning (an athletic apparel company), have failed to gain strong patronage from the U.S. consumers and have had to remove their businesses from the U.S. market (Backaler 2012). For Indian brands, visibility is still low with only one brand (LandRover, acquired by Tata Group) in the top 100 global brands category (Interbrand 2017). Other wellknown Indian brands such as Cafe Coffee Day (café), Airtel (telecom), and Titan (Watch) have successfully launched into Asia, Middle East, and Africa, it has yet to gain traction in the Western market. Given this difficulty and challenge in the midst of growing in globalization, the study findings demonstrated how Asian brands can potentially position their brands in the U.S. marketplace to gain patronage intentions by building the brand's perceived quality and trust.

Several limitations and therefore future research opportunities are noted. First, despite the successful manipulation of a brand's logotype using different languages, the findings showed no statistical significance in the cultural authenticity drawn from the logotype. One factor may have been owing to the fact that both the English and the foreign language were used (compared to English alone), instead of using foreign language alone compared to English. Further study is recommended to assess the role of language use in brand logotype. The comparison between logo marks and logotypes for building cultural authenticity is particularly important to discover as more and more Asian brands are becoming major players in the global marketplace. Second, as much as the researcher tried to account for message variability, the generalization of this study must be done with caution as the study manipulation is limited with a small number of choices for color, shape, and language mix. Future research would be fruitful to find out what other design elements shape cultural authenticity, as well as why and how such cultural authenticity is built via various graphic elements. In addition, as representative of the U.S. general population, the Caucasian segment (who have European ancestries) was the predominant ethnic group. Thus, Asian brands that want to penetrate into a certain minority segment (e.g. 
Americans with Asian ancestries) in the United States may therefore want to further replicate this study focusing on specific minority groups. Thus, further research is recommended to assess consumers' perceptions of Asian cultural authenticity, perceived quality, trust, and patronage intentions within different ethnic minority groups, lifestyles, or residential environments (suburban vs. metropolitan cities).

\section{Disclosure statement}

No potential conflict of interest was reported by the author(s).

\section{Funding}

Margaret Mangel Catalyst Grant from Human Environmental Sciences at University of Missouri.

\section{References}

Aaker, D. A. 1996. Measuring brand equity cross products and markets. California Management Review 38 (3): 102-20.

Agarwal, S., and R. K. Teas. 2001. Perceived value: Mediating role of perceived risk. Journal of Marketing Theory and Practice 9 (4):1-14.

Ailawadi, K. L., and K. L. Keller. 2004. Understanding retail branding: Conceptual insights and research priorities. Journal of Retailing 80 (4):331-42.

Alden, D. L., J. B. E. M. Steenkamp, and R. Batra. 1999. Brand positioning through advertising in Asia, North America, and Europe: The role of global consumer culture. Journal of Marketing 63 (1):75-87.

Alexander, N. 2009. Brand authentication: Creating and maintaining Brand auras. European Journal of Marketing 43 (3/4):551-62.

Backaler, J. 2012. Viewpoint: Why do so few Chinese Brands go global? http://www.bbc.co.uk/news/business-17998321 (accessed April 15, 2017).

Baker, J., A. Parasuraman, D. Grewal, and G. B. Voss. 2002. The influence of multiple store environment cues on perceived merchandise value and patronage intentions. Journal of Marketing 66 (2):120-41.

Barney, J. B., and M. H. Hansen. 1994. Trustworthiness as a source of competitive advantage. Strategic Management Journal 15 (S1):175-90.

Ben-Ur, J., and J. Wang. 2008. From made in China to global Chinese Brand. Journal of International Business and Economics 8 (3):155-8.

Beverland, M. B., and F. J. Farrelly. 2010. The quest for authenticity in consumption: Consumers' purposive choice of authentic cues to shape experienced outcomes. Journal of Consumer Research 36 (5):838-56.

Birnik, A., A. K. Birnik, and J. Sheth. 2010. The branding challenges of Asian manufacturing firms. Business Horizons 53 (5):523-32.

Boisvert, J., and N. J. Ashill. 2011. How Brand innovativeness and quality impact attitude toward new service line extensions: the moderating role of consumer involvement. Journal of Services Marketing 25 (7):517-27.

Brown, S., R. V. Kozinets, and J. F. Sherry. 2003. Teaching old brands new tricks: Retro branding and the revival of Brand meaning. Journal of Marketing 67 (3):19-33.

Cass, J. 2008. Top 7 fonts used by professional in graphic design. http://justcreative.com/2008/09/23/top-7-fontsused-by-professionals-in-graphic-design-2/ (Accessed July 20, 2017).

Cayla, J., and G. M. Eckhardt. 2008. Asian brands and the shaping of a transnational imagined community. Journal of Consumer Research 35(2):216-30.

Chang, H., and S. W. Chen. 2008. The impact of online store environment cues on purchase intention: Trust and perceived risk as a mediator. Online Information Review 32 (6):818-41.

Chaudhuri, A., and M. B. Holbrook. 2001. The chain of effects from Brand trust and Brand affect to Brand performance: The role of Brand loyalty. Journal of Marketing 65 (2):81-93.

Christodoulides, G., L. Chernatony, O. Furrer, E. Shiu, and T. Abimbola. 2006. Conceptualising and measuring the equity of online brands. Journal of Marketing Management 22 (7-8):799-825.

Cohen, E. 1988. Authenticity and commoditization in tourism. Annals of Tourism Research 15 (3):371-86.

Delgado-Ballester, E., and M. Hernández-Espallardo. 2008. Building online brands through Brand alliances in internet. European Journal of Marketing 42 (9/10):954-76.

Dodds, W. B., K. B. Monroe, and D. Grewal. 1991. Effects of price, Brand, and store information on buyers' product evaluations. Journal of Marketing Research 28 (3):307-19.

Dong, L. C., and M. M. Helms. 2001. Brand name translation model: A case analysis of US brands in China. The Journal of Brand Management 9 (2):99-115.

Doyle, J. R., and P. A. Bottomley. 2006. Dressed for the occasion: Font-product congruity in the perception of logotype. Journal of Consumer Psychology 16 (2):112-23.

Eggers, F., M. O’Dwyer, S. Kraus, C. Vallaster, and S. Güldenberg. 2013. The impact of Brand authenticity on Brand trust and SME growth: A CEO perspective. Journal of World Business 48 (3):340-8.

Eisingerich, A. B., and S. J. Bell. 2008. Managing networks of inter-organizational linkages and sustainable firm performance in business-to-business service contexts. Journal of Services Marketing 22 (7):494-504.

Farhoomand, A. 2009. Samsung electronics: Innovation and design strategy. Hong Kong: Asia Case Research Centre. 
Golder, P. N., D. Mitra, and C. Moorman. 2012. What is quality? An integrative framework of processes and states. Journal of Marketing 76 (4):1-23.

Grabe, M. E., and B. H. Westley. ed. 2003. The controlled experiment. In Mass communication research and theory, ed. G. H. Stempel, D. H. Weaver, and G. C. Wilhoit, 267-98. Boston: Allyn and Bacon.

Grayson, K., and R. Martinec. 2004. Consumer perceptions of iconicity and indexicality and their influence on assessments of authentic market offerings. Journal of Consumer Research 31 (2):296-312.

Grewal, D., G. R. Iyer, R. Krishnan, and A. Sharma. 2003. The internet and the price-value-loyalty chain. Journal of Business Research 56 (5):391-8.

Grewal, D., R. Krishnan, J. Baker, and N. Borin. 1998. The effect of store name, Brand name and price discounts on consumers' evaluations and purchase intentions. Journal of Retailing 74 (3):331-52.

Hair, J. F., C. M. Ringle, and M. Sarstedt. 2011. PLS-SEM: Indeed a silver bullet. Journal of Marketing Theory and Practice 19 (2):139-52.

Hem, L. E., and N. M. Iversen. 2003. Transfer of Brand equity in Brand extension: The importance of Brand loyalty. Advances in Consumer Research 30 (1):72-9.

Henderson, P. W., J. A. Cote, S. M. Leong, and B. Schmitt. 2003. Building strong brands in Asia: Selecting the visual components of image to maximize Brand strength. International Journal of Research in Marketing 20 (4): 297-313.

Holbrook, M. B., and K. P. Corfman. 1985. Quality and value in the consumption experience: Phaedrus rides again. Perceived Quality 31 (2):31-57.

Hornikx, J., and F. V Meurs. 2017. Foreign languages as implicit country-of-origin cues in advertising: Mechanism, associations, and effects. Journal of International Consumer Marketing 29 (2):60-73.

$\mathrm{Hu}$, L., and P. M. Bentler. 1999. Cut-off criteria for fit indexes in covariance structure analysis: Conventional criteria versus new alternatives. Structural Equation Modelling: A Multidisciplinary Journal 6 (1):1-55.

Interbrand. 2017. Best brands. Interbrand. https://www.interbrand.com/best-brands/best-global-brands/2017/ (Accessed May 15, 2018).

Jacobs, L., C. Keown, R. Worthley, and K. I. Ghymn. 1991. Cross-cultural colour comparisons: Global marketers beware! International Marketing Review 8 (3):21-31.

Jones, C., and S. Kim. 2010. Influences of retail Brand trust, off-line patronage, clothing involvement and website quality on online apparel shopping intention. International Journal of Consumer Studies 34(6):627-37.

Kaul, S., A. Sahay, and A. Koshy. 2010. Impact of initial-trust-image on shopper trust and patronage intentions: A study of young, male apparel shoppers in India. International Journal of Retail and Distribution Management 38 (4):275-96.
Keeling, K., P. McGoldrick, and S. Beatty. 2010. Avatars as salespeople: Communication style, trust, and intentions. Journal of Business Research 63 (8):793-800.

Keller, K. L. 1993. Conceptualizing, measuring, and managing customer-based Brand equity. The Journal of Marketing 57 (1):1-22.

Kim, D. J., D. L. Ferrin, and H. R. Rao. 2008. A trust-based consumer decision-making model in electronic commerce: The role of trust, perceived risk, and their antecedents. Decision Support Systems 44 (2):544-64.

Kim, J., S. Sharma, and K. Setzekorn. 2002. A framework for building Brand equity online for pure-play B2C retailers and services. International Journal on Media Management 4 (2):123-33.

Korea Times. 2012. Beauty in the East: What it takes to be female flight attendant in Asia. http://www.koreatimes.co. kr/www/news/nation/2012/04/117_108310.html (Accessed September 15, 2017).

Korean Air. 2017. Who we are. Korean Air. https://www. koreanair.com/content/koreanair/global/en/about/who-weare2.html\#history-awards (Accessed September 15, 2017).

Kumar, N., and J. B. E. Steenkamp. 2013. Brand breakout: How emerging market brands will go global. New York, NY: Palgrave MacMillan.

Larsen, S. F., R. W. Schrauf, P. Fromholt, and D. C. Rubin. 2002. Inner speech and bilingual autobiographical memory: A Polish-Danish cross-cultural study. Memory $10(1): 45-54$.

LG Corporation. 2015. History. http://www.lg.com/global/ about-lg/corporate-information/at-a-glance/history (Accessed September 15, 2015).

Madden, T. J., K. Hewett, and M. S. Roth. 2000. Managing images in different cultures: A cross-national study of color meanings and preferences. Journal of International Marketing 8 (4):90-107.

Magnini, V. P., T. Miller, and B. C. Kim. 2011. The psychological effects of foreign language restaurant signs on potential diners. Journal of Hospitality and Tourism Research 35 (1):24-44.

Magnusson, P., S. A. Westjohn, and S. Zdravkovic. 2011. What? I thought Samsung was Japanese: Accurate or not, perceived country of origin matters. International Marketing Review 28 (5):454-72.

Marian, V., and U. Neisser. 2000. Language-dependent recall of autobiographical memories. Journal of Experimental Psychology: General 129 (3):361-8.

Martin, E. 2002. Mixing English in French advertising. World Englishes 21 (3):375-402.

Matzler, K., S. Grabner-Kräuter, and S. Bidmon. 2006. The value-Brand trust-Brand loyalty chain: An analysis of some moderating variables. Innovative Marketing 2 (2): 76-88.

Meyer, E., and E. Y. Shen. 2010. China myths, China facts. Harvard Business Review 88 (1/2):24.

Mayer, R. C., J. H. Davis, and F. D. Schoorman. 1995. An integrative model of organizational trust. Academy of Management Review 20 (3):709-34. 
Miyazaki, A. D., W. M. Lassar, and K. A. Taylor. 2007. Hispanic vs non-Hispanic response to online self-service tasks: Implications for perceived quality and patronage intentions. Journal of Services Marketing 21 (7):520-9.

Munoz, C. L., Wood. N. T., and M. R. Solomon. 2006. Real or blarney? A cross-cultural investigation of the perceived authenticity of Irish pubs. Journal of Consumer Behaviour 5 (3):222-34.

Napoli, J., S. J. Dickinson, M. B. Beverland, and F. Farrelly. 2014. Measuring consumer-based Brand authenticity. Journal of Business Research 67 (6):1090-8.

Ooi, C. S., and B. Stöber. 2008. Authenticity-in-context: Embedding the arts and culture in branding Berlin and Singapore. Copenhagen: Creative Encounters.

Özsomer, A., and S. Altaras. 2008. Global Brand purchase likelihood: A critical synthesis and an integrated conceptual framework. Journal of International Marketing 16 (4):1-28.

Pan, Y., and G. M. Zinkhan. 2006. Determinants of retail patronage: A meta-analytical perspective. Journal of Retailing 82 (3):229-43.

Peñaloza, L. 2000. The commodification of the American West: Marketers' production of cultural meanings at the trade show. Journal of Marketing 64 (4):82-109.

Pittard, N., M. Ewing, and C. Jevons. 2007. Aesthetic theory and logo design: Examining consumer response to proportion across cultures. International Marketing Review 24 (4):457-73.

Rios, R. E., and H. E. Riquelme. 2008. Brand equity for online companies. Marketing Intelligence \& Planning 26 (7):719-42.

Roll, M. 2006. Asian Brand strategy: How Asia builds strong brands. New York, NY: Palgrave Macmillan.

Rose, R. L., and S. L. Wood. 2005. Paradox and the consumption of authenticity through reality television. Journal of Consumer Research 32 (2):284-96.

Saikawa, J., and T. Onisawa. 2014. Logotype design support system based on sketches. Soft Computing in Artificial Intelligence 270:125-42.

Salciuviene, L., P. N. Ghauri, R. S. Streder, and C. Mattos. 2010. Do Brand names in a foreign language lead to different Brand perceptions? Journal of Marketing Management 26 (11-12):1037-56.

Schmitt, B. H. 1995. Language and visual imagery: Issues of corporate identity in East Asia. The Columbia Journal of World Business 30 (4):28-36.

Smith, W. R. 1993. Country-of-origin bias: A regional labelling solution. International Marketing Review 10(6): 4-12.

Song, J. H., and G. M. Zinkhan. 2003. Features of web site design, perceptions of web site quality, and patronage behavior. ACME 2003 Proceedings, Houston, Texas. 106-114.

Southworth, S. S., and M. J. Kim. 2014. Marketing strategies to alleviate risk and build trust for emerging online brands: Case of an Asian cosmetic Brand entering into the USA. Journal of Digital and Social Media Marketing 2 (1):79-90.

Southworth, S. S., and M. J. Kim. 2015. Perceived quality of Asian brands by US consumers: Case of cosmetic Brand using age as a moderator. Advances in International Marketing 26:235-53.

Steenkamp, J. B., R. Batra, and D. L. Alden. 2003. How perceived Brand globalness creates Brand value. Journal of International Business Studies 34 (1):53-65.

Sulwhasoo. 2018. Our history. https://us.sulwhasoo.com/ about-sulwhasoo/origin (Accessed May 15, 2018).

Teas, R. K., and S. Agarwal. 2000. The effects of extrinsic product cues on consumers' perceptions of quality, sacrifice, and value. Journal of the Academy of Marketing Science 28 (2):278-90.

Thompson, C. J., and S. K. Tambyah. 1999. Trying to be cosmopolitan. Journal of Consumer Research 26 (3): 214-41.

Thorson, E., R. Wicks, and G. Leshner. 2012. Experimental methodology in journalism and mass communication research. Journalism \& Mass Communication Quarterly 89 (1):112-24.

Ustinova, I. P., and T. K. Bhatia. 2005. Convergence of English in Russian TV commercials. World Englishes 24 (4):495-508.

Van Riel, C. B., and A. Van Den Ban. 2001. The added value of corporate logos - An empirical study. European Journal of Marketing 35 (3/4):428-40.

Verhagen, T., S. Meents, and Y. Tan. 2006. Perceived risk and trust associated with purchasing at electronic marketplaces. European Journal of Information Systems 15 (6): 542-55.

Waitt, G. 2000. Consuming heritage: Perceived historical authenticity. Annals of Tourism Research 27 (4):835-62.

Yee, C. J., C. S. Ng, and C. H. Khoon. 2011. Consumers' perceived quality, perceived value and perceived risk towards purchase decision on automobile. American Journal of Economics and Business Administration 3 (1): 47-57.

Yoon, S. J. 2002. The antecedents and consequences of trust in online-purchase decisions. Journal of Interactive Marketing 16 (2):47-63.

Yorkston, E., and G. Menon. 2004. A sound idea: Phonetic effects of Brand names on consumer judgments. Journal of Consumer Research 31 (1):43-51.

Zeithaml, V. A. 1988. Consumer perceptions of price, quality, and value: A means-end model and synthesis of evidence. Journal of Marketing 52 (3):2-22.

Zhang, Y., L. Feick, and L. J. Price. 2006. The impact of self-construal on aesthetic preference for angular versus rounded shapes. Personality and Social Psychology Bulletin 32 (6):794-805.

Zhou, K. 2011. Herborist: A Chinese personal care Brand goes abroad. Hong Kong: Asia Case Research Centre. 